\title{
Fuzzy Multi Criteria Approach for Selecting Software Quality Model
}

\author{
Ritika Kohli \\ Post Graduate Student \\ Guru Nanak Dev Engineering College, Ludhiana
}

\author{
Sumeet Kaur Sehra \\ Assistant Professor \\ Guru Nanak Dev Engineering College, Ludhiana
}

\begin{abstract}
Software Quality models have been proposed to evaluate general and definite type of software products. These models were proposed to evaluate scope of software product. There has been an increasing interest in recent times for using Multi Criteria Decision making techniques to present the comparison of Software Quality models. Earlier Analytic Hierarchy Process (AHP) has been used by researchers. The use of Fuzzy Prioritization Method for this offers several advantages when compared to other commonly used techniques. In Fuzzy Analytic Hierarchy Process elements of the group pairwise comparison matrices are presented as fuzzy numbers in order to model uncertainty and imprecision in the Decision Maker's (DM) judgments. In this paper Fuzzy AHP is concluded with study of selection of Software Quality model.
\end{abstract}

\section{Keywords}

Software Quality Models, Multi-Criteria Decision Making, Analytic Hierarchy Process (AHP), Fuzzy AHP, McCall Model, Boehm's Model, ISO9126 Model .

\section{INTRODUCTION}

Software has become a key component of business systems, products and services. Thus quality of software product is absolutely necessary for business success. ISO9126 defines Software Quality as "a set of attributes of software product by which its quality is described and evaluated." Software Quality models have become well preferred means to describe and manage software quality. Different Software Quality models [1] have been proposed to help measure the quality of software products. These quality models consist of number of quality characteristics that reflects the quality of software products from view of that characteristic. In this work, Software Quality models namely McCall Model, Boehm Model and ISO9126 have been discussed. In addition, focus is also given on comparison between these quality models using Fuzzy AHP.

McCall [2] model developed in 1977 is the oldest software quality model with a volume of 55 quality characteristics and are called "factors". These factors have been flattened into eleven main factors defined to three major perspectives, product revision, product transition and product operation. New factors have been added to original and some have been redefined [3].

Boehm model [4] attempted to qualitatively define software quality by predefined set of attributes and metrics. It was represented as a hierarchical structure of characteristics that contributed to total quality. It had seven quality factors that represented qualities expected from a software system.
The method to develop a software quality models have been based on comparisons between selected well known models so that it is easy to customize the close model to intended scope. ISO9126 is an example. This study presents Fuzzy AHP as a proposed method for selecting the software quality model. This method can handle qualitative criteria [4] that are difficult to describe in crisp values. Analytic Hierarchy Process offers a method for making adjustments in such situations. The judgments in AHP are relative by nature, altering the set of alternatives may change the decision score of all alternatives. Thus Fuzzy AHP is used to resolve the subjectivity and the vagueness of AHP and can be used for selecting the type of Model best suited for an organization in terms of quality factors required. A range of values is used to incorporate DM's improbability. The DM can select the value that specifies his attitude like optimistic, pessimistic or moderate.

Further, this paper is organized as follows. The Software Quality Models have been discussed for using Multi Criteria decision-making approach in the subsequent section. After which discussion related to effectiveness of MCDM methods is presented. The DM's have been chosen from the small companies and were asked to do the necessary required comparison between different factors of the model as would be conferred in the proceeding sections. The final section concludes the research and future directions discussed.

\section{SOFTWARE QUALITY MODELS}

\subsection{McCall's Software Quality Model}

One of the more well-known predecessors of today's quality models is the quality model presented by Jim McCall in 1977.The McCall Model aimed at system developers. It is used during development process. It addresses 3 areas of software work: 1) Product Operation (its operation characteristics). 2) Product Revision (ability to undergo changes).3) Product Transition (adaptability to new environments) [5].It covers portability, reusability and interoperability criteria. This model is proposed for general application systems, and thus the domain specific attributes are not explicitly addressed in the scope of the model.

\subsection{Boehm's Software Quality Model}

Boehm introduced this model in 1978 to evaluate the quality of software both quantitatively and automatically. He attempted to define the quality of software by predefined set metrics. This model represents a hierarchical structure of characteristics that contribute to total quality. Boehm's seven quality factors represent the qualities expected from a software system. These are Portability, Reliability, Efficiency, Usability, Testability, Understandability and Flexibility. 


\subsection{ISO 9126 Software Quality Model}

The ISO9126 model is proposed as an international standard for software quality measurement. It is a derivation of the McCall model. ISO9126 specifies and evaluates the quality of software in terms of internal and external software qualities and their connection to the attributes. It defines 21 attributes which are arranged in six areas: Functionality, Reliability, usability, efficiency, maintainability and portability. Software quality measurement techniques help us to measure some attributes. Table1 represents the attributes common to McCall, Boehm and ISO9126 model.

Table1: Comparison between Different Software Quality Models.

\begin{tabular}{|l|c|c|c|}
\hline \multicolumn{1}{|c|}{ Quality } \\
$\begin{array}{c}\text { Characterist } \\
\text { ics }\end{array}$ & Boehm & McCall & $\begin{array}{c}\text { ISO } \\
\mathbf{9 1 2 6}\end{array}$ \\
\hline Efficiency & $\mathrm{X}$ & $\mathrm{X}$ & $\mathrm{X}$ \\
\hline Reliability & $\mathrm{X}$ & $\mathrm{X}$ & $\mathrm{X}$ \\
\hline $\begin{array}{l}\text { Maintainabili } \\
\text { ty }\end{array}$ & $\mathrm{X}$ & $\mathrm{X}$ & $\mathrm{X}$ \\
\hline
\end{tabular}

\section{MULTI CRITERIA DECISION MAKING METHOD}

Multi criteria decision making is a way to deal with the process of making decision among number of alternatives with differing criteria on them. Fuzzy AHP is an extension of original AHP method recommended by Saaty [5] to deal with quantitative and qualitative data. AHP and Fuzzy AHP are explained in section 3.1 and 3.2 respectively.

\subsection{Analytic Hierarchy Process}

AHP has been applied in many suggested decision area. This method can be applied to solve many complex problems. Using AHP, the complex problem is composed into several sub problems in terms of hierarchical levels among the goal, dimensions (attributes) and alternatives.

The decision maker in AHP states judgments in terms of pairwise comparisons on each level of hierarchy with respect to their effect on the next level. Saaty's AHP is renowned decision making analytical tool used for modelling unstructured problems in various domains [6-8]. Saaty's scale is used to calculate a numerical rating. The verbal judgments made by the decision maker are interpreted into numbers as utilized in Table2 [9].

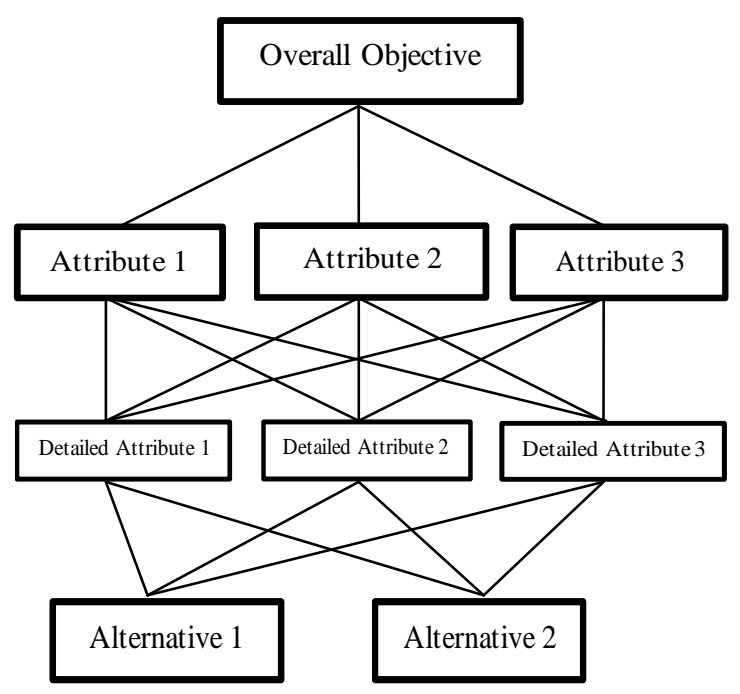

Fig 1. Structure of Analytic Hierarchy Process

Table2: Saaty's Scale

\begin{tabular}{|c|c|}
\hline $\begin{array}{c}\text { Intensity of } \\
\text { Importance }\end{array}$ & Definition \\
\hline 1 & Equal Important \\
\hline 3 & Much More important \\
\hline 5 & Very much more important \\
\hline 7 & Absolutely more important \\
\hline 9 & Intermediate values \\
\hline $2,4,6,8$ & \\
\hline
\end{tabular}

\subsection{Fuzzy Analytic Hierarchy Process}

Fuzzy AHP method [10] is an advanced analytical method which is developed from AHP. Though AHP has been popular still it has been criticized for its inability to adequately handle the inherent uncertainty and imprecision associated with mapping of the DM's perception to exact numbers. In Fuzzy AHP, the fuzzy comparison ratios are used to be able to tolerate the imprecision [11]. The problem with AHP is that in some situations the DM wants to use the uncertainty while making comparisons of the alternatives. Fuzzy numbers are used instead of crisp numbers [12] for taking uncertainties into consideration.

\subsubsection{Fuzzy Numbers}

Among the various shapes of fuzzy number, triangular fuzzy number is the most popular among the various shapes of fuzzy numbers (Trapezoidal fuzzy number, Gaussian fuzzy number and many more).The idea of using fuzzy triangular number is to give decision maker an opportunity so he can decide in a better way if there is little uncertainty in deciding the supremacy of one alternative over another. The elegant approach to deal with imprecision of fuzzy set theory was proposed by Lotfi Zadeh [14]. In his approach an element can belong to a set to a degree $\mathrm{k}(0 \leq \mathrm{k} \leq 1)$. The degree to which the elements are the members of the interval known as the 
membership function is as given as [13]. The Triangular membership function is given in Fig. 2.

$\mu_{\mathrm{A}}(\mathrm{x})=\left\{\begin{array}{l}\mathrm{O} \text { for } x \leq l \\ \frac{x-l}{m-l} \text { for } l \leq x \leq m \\ \frac{u-x}{u-m} \text { for } m \leq x \leq u \\ 0 \text { for } x \geq n\end{array}\right\}$

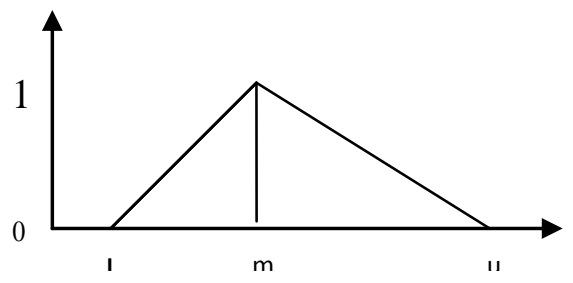

Fig. 2 Triangular Membership Function

The Triangular Fuzzy Numbers(TFN) is a fuzzy number represented with three points

$\mathrm{a}_{i j}=\left(\mathrm{l}_{i j}, \mathrm{~m}_{i j}, \mathrm{u}_{i j}\right)$

Here 1 is the lower limit value, $m$ is the most promising value and $\mathrm{u}$ is the upper limit value. The fuzzy comparison matrix differs with Saaty's Scaling in which membership scales are used instead of the 1-9 scales. This research used linguistic variables that are used to express situation that are difficult to define. Table 3 shows membership function of linguistic scales that has been applied in this study.

The theory of fuzzy sets has extended outmoded mathematical decision theories therefore it can be employed without any imprecision problems. Human beings make use of Linguistic environment for handling decision making problems. Fuzzy AHP does not require any consistency mechanism as applied in other research applications [15].

Table 3: Membership Functions of Linguistic Scales

\begin{tabular}{|c|l|c|c|}
\hline $\begin{array}{l}\text { Fuzzy } \\
\text { Number }\end{array}$ & $\begin{array}{l}\text { Linguistic } \\
\text { scale }\end{array}$ & TFN & Inverse TFN \\
\hline 1 & $\begin{array}{l}\text { Equal } \\
\text { Important }\end{array}$ & $(1,1,3)$ & $(1,1,1 / 3)$ \\
\hline 3 & $\begin{array}{l}\text { Weakly } \\
\text { important }\end{array}$ & $(1,3,5)$ & $(1 / 5,1 / 3,1)$ \\
\hline 5 & $\begin{array}{l}\text { Essentially } \\
\text { important }\end{array}$ & $(3,5,7)$ & $(1 / 7,1 / 5,1 / 3)$ \\
\hline 7 & $\begin{array}{l}\text { Very Strongly } \\
\text { important }\end{array}$ & $(5,7,9)$ & $(1 / 9,1 / 7,1 / 5)$ \\
\hline 9 & $\begin{array}{l}\text { Absolutely } \\
\text { important }\end{array}$ & $(7,9,9)$ & $(1 / 9,1 / 9,1 / 7)$ \\
\hline
\end{tabular}

3.2.2 Calculation of Fuzzy weights from Comparison

\section{Matrices}

Using the values of scales and fuzziness given in Table 3, a fuzzy comparison matrix $A=\left(a_{i j}\right)_{n x n}$ where $\mathrm{i}, \mathrm{j}=1,2,3,4 \ldots \mathrm{n}$ is constructed. The TFN value of an element in matrix $A$ is decided by the DM based on the Saaty's values presented in Table 2 and fuzziness ranges of Table 3 . After obtaining fuzzy matrix, priority weights are calculated. To estimate the weight values for each criterion and for each alternative with reference to a given criteria, the synthetic extent values are obtained given as under

$S_{i}=\sum_{j=1}^{m} N_{c i}^{j} \otimes\left[\sum_{i=1}^{n} \sum_{j=1}^{m} N_{c i}^{j}\right]^{-1}$

Where $N_{c i}^{j}, \mathrm{j}=1,2,3 \ldots \mathrm{n}$ are TFN values and $\otimes$ is fuzzy multiplication operation. The degree of possibility of $N_{1} \geq N_{2}$ is defined as,

$V\left(N_{1} \geq N_{2}\right)=\sup _{x \geq y}\left[\min \left(\mu_{N_{1}}(x), \mu_{N_{2}}(y)\right)\right]$

When a pair $(x, y)$ exists such that $x \geq y$ and $\mu_{N_{1}}(x)=\mu_{N_{2}}(y)=1$, then $V\left(N_{1} \geq N_{2}\right)=1$. Since the numbers $N_{1}$ and $N_{2}$ are convex fuzzy numbers so,

$V\left(N_{1} \geq N_{2}\right)=1$ if $n_{11} \geq n_{21}$

$V\left(N_{2} \geq N_{1}\right)=h g t\left(N_{1} \cap N_{2}\right)=\mu_{N_{1}}(d)$

Where $d$ is ordinate of the highest intersection point $D$ between $\mu_{N_{1}}$ and $\mu_{N_{2}}$. When $N_{1}$ and $N_{2}$ are fuzzy numbers then ordinate of $\mathrm{D}$ is computed as

$V\left(N_{2} \geq N_{1}\right)=\operatorname{hgt}\left(N_{1} \cap N_{2}\right)=\frac{l_{1}-u_{2}}{\left(m_{2}-l_{2}\right)-\left(m_{1}-l_{1}\right)}$

For the comparison of $N_{1}$ and $N_{2}$, both the values of $V\left(N_{1} \geq N_{2}\right)$ and $V\left(N_{2} \geq N_{1}\right)$ are required. The degree possibility for a convex fuzzy number to be greater than $\mathrm{k}$ convex fuzzy numbers $N_{i}(i=1,2, \ldots, k)$ is defined by $V\left(N \geq N_{1}, N_{2}, \ldots, N_{k}\right)=V\left[\left(N \geq N_{1}\right), \ldots,\left(N \geq N_{k}\right)\right]=\min V\left(N \geq N_{i}\right)$ If $m\left(A_{i}\right)=\min V\left(S_{i} \geq S_{k}\right)$, for $k=1,2, \ldots, n ; k \neq i$, then the $W_{p}$, the weight vector is given by, $W_{A}=\left(m\left(A_{1}\right), m\left(A_{2}\right), \ldots, m\left(A_{n}\right)\right)^{T}$ where $\quad A_{i}(i=1,2, \ldots, n) \quad$ are $n$ elements. In order to normalize the weight vector $W_{A}$ the following formula is used.

$W_{A}=\frac{W^{T}}{\left(\sum W^{T}\right)}$

\section{CALCULATING WEIGHTS FOR DIFFERENT SOFTWARE QUALITY MODELS}

The initial stage is identification of the necessary criteria, which would be used to evaluate the different models in comparison with each other. The criteria identified are given follows:

a. Reliability (C1): It tells us the behavior of the models corresponding to different situations. It reflects design perfection rather than manufacturing perfection.

b. Efficiency (C2): It deals with the attributes that describe the performance of software with respect to resource and time utilization.

c. Maintainability (C3): It is the ability of the component to be modified. 


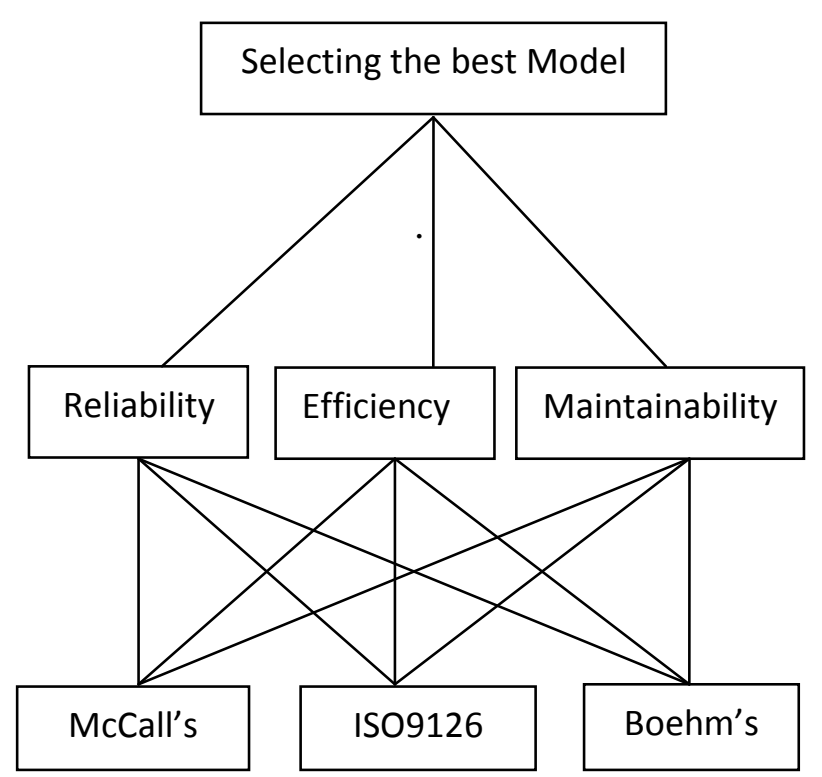

Fig 3. The Hierarchy of Software Quality Models

After selecting the criteria, the alternatives are considered, these are, McCall, Boehm or ISO 9126 software quality models. The Decision Makers (DMs) were asked to make preferences between the pair criteria after providing the necessary information regarding criteria and decision alternatives and then pair of alternatives over the different criteria based. The decision Makers were asked to fill a questionnaire about the criterion and alternative and then after it matrix table 4 and table 5 are created using triangular fuzzy numbers are created to make fuzzy pairwise comparison. It is also difficult to give the some of the preferences as crisp values, so for such uncertainty the fuzzy comparison matrix is created.

Table 4: Fuzzy matrix of criteria with respect to Goal

\begin{tabular}{|c|c|c|c|}
\hline & C1 & C2 & C3 \\
\hline C1 & {$[1,1,1]$} & {$[1 / 7,1 / 5,1 / 3]$} & {$[3,5,7]$} \\
\hline C2 & {$[5,7,9]$} & {$[1,1,1]$} & {$[1 / 9,1 / 7,1 / 5]$} \\
\hline C3 & {$[1 / 7,1 / 5,1 / 3]$} & {$[5,7,9]$} & {$[1,1,1]$} \\
\hline
\end{tabular}

Table 5: Fuzzy Pairwise Comparisons of alternatives with respect to criteria

\begin{tabular}{|c|c|c|c|}
\hline C1 & A1 & A2 & A3 \\
\hline A1 & {$[1,1,1]$} & {$[1 / 7,1 / 5,1 / 3]$} & {$[3,5,7]$} \\
\hline A2 & {$[3,5,7]$} & {$[1,1,1]$} & {$[1,3,5]$} \\
\hline A3 & {$[1 / 7,1 / 5,1 / 3]$} & {$[1 / 5,1 / 3,1]$} & {$[1,1,1]$} \\
\hline
\end{tabular}

\begin{tabular}{|c|c|c|c|}
\hline $\mathbf{C 2}$ & $\mathbf{A 1}$ & $\mathbf{A 2}$ & $\mathbf{A 3}$ \\
\hline $\mathbf{A 1}$ & {$[1,1,1]$} & {$[1,1,1]$} & {$[1,1,1]$} \\
\hline $\mathbf{A 2}$ & {$[1,1,1]$} & {$[1,1,1]$} & {$[1 / 5,1 / 3,1]$} \\
\hline $\mathbf{A 3}$ & {$[1,1,1]$} & {$[3,5,7]$} & {$[1,1,1]$} \\
\hline
\end{tabular}

\begin{tabular}{|c|c|c|c|}
\hline C3 & A1 & A2 & A3 \\
\hline A1 & {$[1,1,1]$} & {$[3,5,7]$} & {$[1 / 7,1 / 5,1 / 3]$} \\
\hline $\mathbf{A 2}$ & {$[1 / 7,1 / 5,1 / 3]$} & {$[1,1,1]$} & {$[5,7,9]$} \\
\hline $\mathbf{A 3}$ & {$[3,5,7]$} & {$[1 / 9,1 / 7,1 / 5]$} & {$[1,1,1]$} \\
\hline
\end{tabular}

The first stage of weight calculation process is the aggregation of $\mathrm{l}_{\mathrm{ij}}, \mathrm{m}_{\mathrm{ij}}$ and $\mathrm{u}_{\mathrm{ij}}$ values present in the pairwise comparison matrix for judgments between criteria calculated as the row sums and the column sums as in table 6 .

Table 6: Sum of rows and columns based on criteria's

\begin{tabular}{|c|c|c|}
\hline & Rows Sum & Column Sum \\
\hline C1 & $(4.14,6.20,8.33)$ & $(6.14,8.20,10.33)$ \\
\hline C2 & $(6.11,8.14,10.20)$ & $(6.14,8.20,10.33)$ \\
\hline C3 & $(6.14,8.20,10.33)$ & $(4.11,6.14,8.20)$ \\
\hline \multicolumn{3}{|c|}{ Sum of Column Sums } \\
\hline
\end{tabular}

The synthetic extent $S_{i}$ is calculated for given criterion is calculated as:

$S_{1}=\left[\frac{4.14}{28.86}, \frac{6.20}{22.54}, \frac{8.33}{16.39}=(0.143,0.275,0.508)\right]$

$S_{2}=\left[\frac{6.11}{28.86}, \frac{8.14}{22.54}, \frac{10.20}{16.39}=(0.211,0.361,0.622)\right]$

$S_{3}=\left[\frac{6.14}{28.86}, \frac{8.20}{22.54}, \frac{10.33}{16.39}=(0.212,0.363,0.632)\right]$

By using equations (7) and (8) the raw weights using synthetic extent are calculated in Table 7 here under: 
Table 7 Raw weights based on different criteria

\begin{tabular}{|c|c|c|c|c|}
\hline \multicolumn{4}{|c|}{ Synthetic Index } & \multirow{2}{*}{$\begin{array}{l}\text { Raw } \\
\text { weights }\end{array}$} \\
\hline & $\mathbf{S}_{1}$ & $\mathbf{S}_{2}$ & $\mathbf{S}_{3}$ & \\
\hline $\begin{array}{l}V\left(S_{1} \geq\right. \\
\left.S_{2}, S_{3}\right)\end{array}$ & - & 0.774 & 0.76 & 0.76 \\
\hline $\begin{array}{l}\mathbf{V}\left(\mathbf{S}_{2} \geq\right. \\
\left.\mathbf{S}_{1}, \mathbf{S}_{3}\right)\end{array}$ & 1 & - & 0.99 & 0.99 \\
\hline $\begin{array}{l}V\left(S_{3} \geq\right. \\
\left.S_{1}, S_{2}\right)\end{array}$ & 1 & 1 & - & 1 \\
\hline
\end{tabular}

After normalization of the weights, the weights of $\mathrm{C}_{1} \mathrm{C}_{2}$ and $\mathrm{C}_{3}$ are $\mathrm{W}=(0.27,0.35,0.36)$. We used the same method for calculating the weights for given criteria. The outcome is given in Table 8.

Table 8: Set of Weights for all fuzzy matrices

\begin{tabular}{|c|l|l|l|l|}
\hline & \multicolumn{3}{|l|}{$\begin{array}{l}\text { Weights of Decision } \\
\text { Alternatives }\end{array}$} & $\begin{array}{l}\text { Weights for } \\
\text { criteria }\end{array}$ \\
\hline & $\mathrm{A}_{1}$ & $\mathrm{~A}_{2}$ & $\mathrm{~A}_{3}$ & \\
\hline $\mathrm{C}_{1}$ & 0.43 & 0.55 & 0.013 & 0.27 \\
\hline $\mathrm{C}_{2}$ & 0.23 & 0.19 & 0.56 & 0.35 \\
\hline $\mathrm{C}_{3}$ & 0.30 & 0.39 & 0.30 & 0.36 \\
\hline Final Results & 0.32 & 0.38 & 0.29 & \\
\hline
\end{tabular}

The results in the Table 8 disclose that the Decision Maker prefers ISO 9126 as the model for estimating Software Quality requirements.

\section{CONCLUSION}

In Software engineering, selection of a software quality model is critical, which may affect the quality of software according to the model selected. The aim of this study is to inspect the application of Fuzzy AHP method for selecting the best model based on the requirements of the company. The decision makers used this approach to identify the weight of each criterion. Since fuzzy sets are inevitable in representing uncertainty, vagueness and human subjectivity. This study provides us a view of existing models, important factors and a convenient method to tackle multi criteria decision making problem. Fuzzy AHP aids in solving research problems through a structured manner and a simple process. Future research regarding this can be used for sub criteria's of the given models to stabilize a model in real sense of software engineering scenario.

\section{REFERENCES}

[1] Franch, X. and Carvallo, J.P., "Using Quality Models in Software Package Selection," IEEE Software, vol. 20, no. 1, pp. 34-41, Jan/Feb., 2003.

[2]McCall, J.A., Richards, P.K., Walters, G.F.: Factors in Software Quality, Griffiths Air Force Base, N.Y. Rome Air Development Center Air Force Systems Command (1977).

[3] AL-Badareen, A.B., Selamat, M.H., Jabar, M.A., Din, J., Turaev, S., Malaysia, S.: Users' Perspective of Software Quality. In: The 10th WSEAS International Conference on Software Engineering, Parallel And Distributed Systems (SEPADS 2011), pp. 84-89.

[4] Noor, N.M.M, Sabri, I.A.A, Hitam, M.S., Ali, H.N. (2010),"Intelligent Decision Support System for Tourism Destination Choice", in Proceedings of the 4th
International Symposium of Information Technology.2010.KL Convention Centre: IEEE

[5] Saaty, T.L., Decision making with Dependence and Feedback: Analytic Network Process, RWS Publications, Pittsburgh, 2001.

[6] Hsu, T.-H. and F.F.C. Pan, Application of Monte Carlo AHP in ranking dental quality attributes, Expert Systems with Applications, 2009. 36(2, Part 1): p. 2310-2316.

[7] Kamal M. Al-Subhi, A.-H., Application of the AHP in project management, International Journal of Project Management, 2001. 19(1): p. 19-27.

[8] Lee, S.K., G. Mogi, and J.W. Kim, The competitiveness of Korea as a developer of hydrogen energy technology: The AHP approach, Energy Policy, 2008. 36(4): p. 12841291

[9] Saaty, T.L., "A scaling method for priorities in hierarchical structures", Journal of Mathematical Psychology, 1977.15(3):p.234-281.

[10]Zhu, K. J., Jing, Y., and Chang, D. Y., "A Discussion on Extent Analysis Method and Applications of FuzzyAHP”, European Journal of Operational Research,116,1999, pp. 450-456.

[11] F.Ozgur Catak, Servet Karabas, Serkan Yildirim, "Fuzzy Analytic Hierarchy Based DBMS Selection in Turkish National Identity Card management project", IJIS vol.2,no.4,July 2012

[12] Mishra, S.K. and Ray, A.(2012) "Software developer selection : a Holistic approach for an eclectic decision" International Journal of Computer Application, volume 47-No.1,June 2012.pp.12-18.

[13] Schank, R. 1982. Dynamic Memory: A theory of reminding and learning in computers and people. New York, NY: Cambridge University Press. 95-109.

[14] L. Zadeh: Fuzzy sets, Information and Control, 8, 338-353, 1965.

[15] Hsieh, T-Y., Lu, S-T. and Tzeng, G-H., Fuzzy MCDM approach for planning and design tenders selection in public office buildings, International Journal of Project Management, 2004. 22(7): p. 573-584

[16]Tomar. A.B. and Thakre. V.M., "A SYSTEMATIC STUDY OF SOFTWARE QUALITY MODELS", International Journal of Software Engineering \& Applications (IJSEA), Vol.2, No.4, October 2011.

[17] Khaddaj, S.H., Gerard. London, "A Proposed Adaptable Quality Model for Software Quality Assurance”, Journal of Computer Sciences 1 (4): 482-487, 2005, ISSN 15493636, Science Publications, 2005.

[18]Capra, E., Francalanci, C., Merlo, F., "An Empirical Study on the Relationship Between Software Design Quality, Development Effort and Governance in Open Source Projects," IEEE Transactions on Software Engineering, 05 Aug 2008, IEEE computer Society Digital Library. IEEE Computer Society, 11 October 2008.

[19]Hunaity, M.A.L., "Towards an Efficient Quality Based Web Service Discovery Framework services", pp.261264, 2008 IEEE Congress on Services - Part I, 2008. 